\title{
Calcium cell signalling and cataract: role of the endoplasmic reticulum
}

\begin{abstract}
The lens possesses an impressive array of G-protein receptors that are coupled to the release of intracellular calcium. They include members of the muscarinic, adrenergic and purinergic families and activation of the former has been implicated in cataract for some time. There are several possible mechanisms whereby activation of such receptors could give rise to cataract. $A$ prolonged increase in intracellular calcium would be expected to activate proteases such as calpain and so could induce unscheduled and irreversible breakdown of important structural proteins. It has recently been shown that activation of G-protein receptors also modulates lens cell growth, and any interference with the highly controlled pattern of cell growth and development within the lens is also likely to have catastrophic consequences. If the calcium store is totally inactivated in lens cells, for example by exposure to thapsigargin, then growth ceases. This finding provides a means of inhibiting the lens cell growth which leads to posterior capsular opacification (PCO). For example, it has been shown that thapsigargin-coated intraocular lenses totally inhibit lens cell growth within cultured capsular bags, and if this technology could be transferred to the clinic then it could provide a simple and relatively inexpensive means of preventing PCO.
\end{abstract}

Key words Calcium, Cataract, Cell signalling, Endoplasmic reticulum, Posterior capsular opacification

Although almost no two human cataractous lenses are the same, either in appearance or in underlying molecular and ionic changes, ${ }^{1,2}$ it is recognised that there are three major types which involve nuclear, cortical and posterior subcapsular opacities. ${ }^{3}$ The last are most common in younger age groups ( $<60$ years) and are often associated with medical treatment such as long-term steroid therapy. ${ }^{4}$ Nuclear changes, however, appear to occur mainly in later life ( $>60$ years) and are accompanied by oxidative changes in both lens glutathione and major crystallins within the nuclear regions. ${ }^{5}$ Interestingly, a recent study carried out in England has revealed that babies with a lower than average body weight 1 year after birth have a significantly increased risk of developing nuclear cataract 60 years later. ${ }^{6}$ In these cases the future nuclear regions may be assembled with an increased susceptibility to oxidative insult. However, it also appears from separate surveys carried out in Finland and America that an increased intake of dietary antioxidants (especially vitamins $C$ and $E$ ) provides a certain protection against developing nuclear cataract late in life. ${ }^{7,8}$ The very interesting aspects of this type of cataract are that the oxidative changes that occur are strictly confined to the nuclear regions, far removed from any primary oxidative insult such as hydroxen peroxide emanating from the aqueous humour. ${ }^{9}$ However, it does appear that these deep regions can receive protective influences from the surrounding humours. In pure nuclear cataracts, these changes occur without concomitant alterations in the total protein content, ionic distribution or membrane permeability properties of the lens ${ }^{2,5}$ and hence they are quite unlike the nuclear cataracts produced by oxidative selenium toxicity in animal model systems, for example, where catastrophic changes in lens proteins and ions occur in very young lenses. ${ }^{10}$

The changes in human nuclear cataracts are also, of course, quite unlike those that occur in pure cortical cataracts where the white lightscattering opacities in the lens cortex are accompanied by very significant protein losses and changes in ionic distribution and membrane permeability properties. ${ }^{11}$ The possible roles for calcium in human cortical cataract will be discussed in this review; it should be remembered that the vast majority of experimental cataracts in animals, whether induced by X-rays, UV light or diabetes, all produce typical white, light-scattering areas in the lens cortex. At present there does not appear to be an adequate animal model that produces nuclear changes occurring some considerable time after the birth of the animal. It should also be noted that as far as human cataractous lenses are concerned, many show changes in the nuclear, cortical and polar regions of the lens. 
This mixed nature of the cataracts renders a detailed investigation of any of the single mechanisms extremely difficult. $^{2}$

\section{Calcium and cataract}

The total calcium content of the lens is normally approximately one-tenth that of the surrounding humours, but the free calcium, measured by calcium electrodes, is almost 1000 -fold less than the external free value. This ionic gradient is considerably greater than any of the gradients for the commonly occurring ions. This very asymmetrical free calcium distribution appears to be common to all cell types and is present across both epithelial and fibre cell membranes. A loss of this gradient inevitably results in the death of the cell, whether in a controlled manner by apoptosis or simply by necrosis. ${ }^{11}$ In the lens an increase in internal calcium can be induced by a very large number of processes: by oxidation, either of external or internal sulphydryl groups, ${ }^{12}$ by removal of external glucose ${ }^{11}$ perversely, by reducing external calcium ${ }^{13}$ and, in a gradual manner, by age itself. ${ }^{14}$ The end result of the calcium increase by whatever means is an increase in light scatter in the lens and, in those systems in which it has been investigated, a concomitant loss of lens proteins. ${ }^{10,11,15}$ This loss appears to be due to activation by calcium of an enzyme cascade where one possible participant is calpain although others may play a role. The importance of calcium can be seen in lens organ culture studies where, if EGTA is added to the external medium to bind calcium, then there is no loss of protein. Light scatter is also greatly reduced, even in lenses that have become grossly swollen due to an uptake of sodium and water. ${ }^{15}$ It has been recognised for some time that, in human cortical cataracts and in experimental model systems, total and free calcium rise in tandem. ${ }^{1,2,11,15}$ Interestingly, calcium electrode studies carried out on human lenses have shown that in those with localised cataracts that the free calcium only rises in the opaque areas, whereas surrounding clear regions have near-normal free calcium levels. ${ }^{11}$ This is also true in the diabetic rat lens, for example, where the cataract is produced in vivo and the calcium measurements are made in vitro. ${ }^{16}$

Human lenses with small localised opacities also appear to have suffered a significant increase in total calcium before a sodium increase is involved and this implies a more subtle role for calcium than a mere harbinger of total cell death. ${ }^{11}$ Recent experiments concerning calcium cell signallng systems in the lens have begun to reveal what this subtle role might be. ${ }^{17}$

\section{Calcium cell signalling}

Vivekanandan and Lou ${ }^{18}$ first showed that the lens possesses many of the enzymes necessary to both produce and degrade the critical calcium cell signalling messenger, inositol $(1,4,5)$ trisphosphate $\left(\mathrm{IP}_{3}\right)$. Importantly, $\mathrm{IP}_{3}$ can be released from membrane phospholipids upon activating both tyrosine kinase and
G-protein coupled receptor systems. Agonists for the former include a range of growth factors that have already been shown to play a role in normal lens development, differentiation and cataract formation, and these include FGF and PDGF. ${ }^{19-21}$ Agonists for the latter include a host of molecular species that are more associated with the dynamic aspects of nerve and muscle function than with the functional activity of the lens. Such factors include acetylcholine, adrenaline, histamine and ATP. ${ }^{17}$ Over recent years it has been shown that tissue-cultured human lens cells respond to all of the above with typical calcium cell-signalling oscillations. ${ }^{17,22}$ Exposure of the whole rabbit lens to acetylcholine, for example, can also induce typical voltage oscillations $^{23}$ and the human lens is capable of responding to acetylcholine throughout life. ${ }^{24}$ Classically there are two types of receptors involved in acetylcholine signalling - the nicotinic and muscarinic systems - and it is the latter that initiates calcium signalling in human lens cells. ${ }^{17}$

\section{Calcium cell signalling and the growth of the lens}

It has been recognised for some time that many of the growth factors that modulate cell growth, including FGF, PDGF and HGF, also mobilise calcium from intracellular stores, and some of the above have been shown to mobilise calcium from intracellular stores in human lens cells. ${ }^{17}$ Fetal calf serum is a most potent growth-inducing agent in cells and exposure to this agent also induces typical calcium signalling oscillations in lens cells. ${ }^{17,25}$ Since the endoplasmic reticulum ATPase inhibitor thapsigargin totally abolishes calcium signalling in human lens cells (Fig. 1), it is possible to answer the question of the significance of the role of calcium in driving lens cell growth. In fact, it appears from $\left[{ }^{3} \mathrm{H}\right]$ thymidine studies that the store plays a vital role in controlling cell growth (at least under in vitro conditions). Significantly, while low concentrations (nanomolar) of

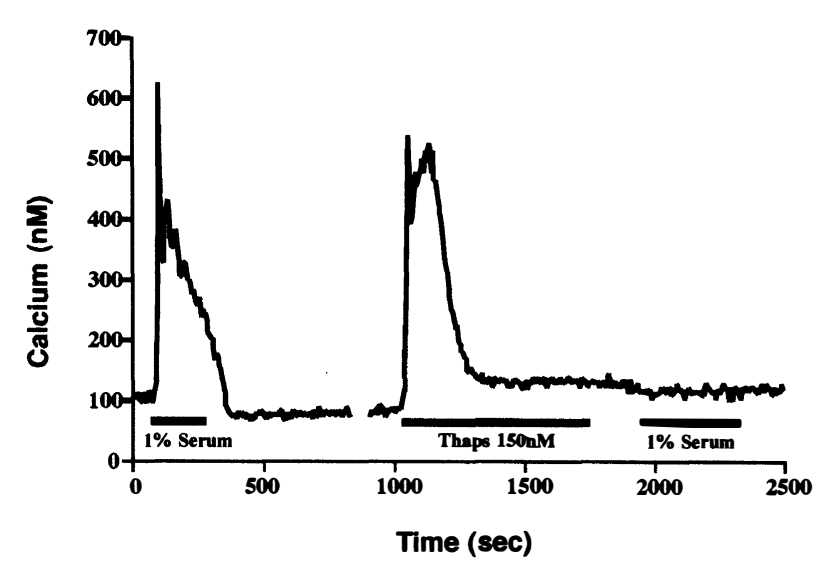

Fig. 1. Effect of thapsigargin (Thaps) on agonist-induced calcium mobilisation in human lens cells. Primary human lens epithelial cells were seeded and cultured on glass coverslips before Fura-2 incorporation. Fluorescence ratios were monitored using a PTI imagescan system and converted to give a measure of internal calcium. ${ }^{22}$ Note that thapsigargin totally abolishes the serum-induced calcium response. 


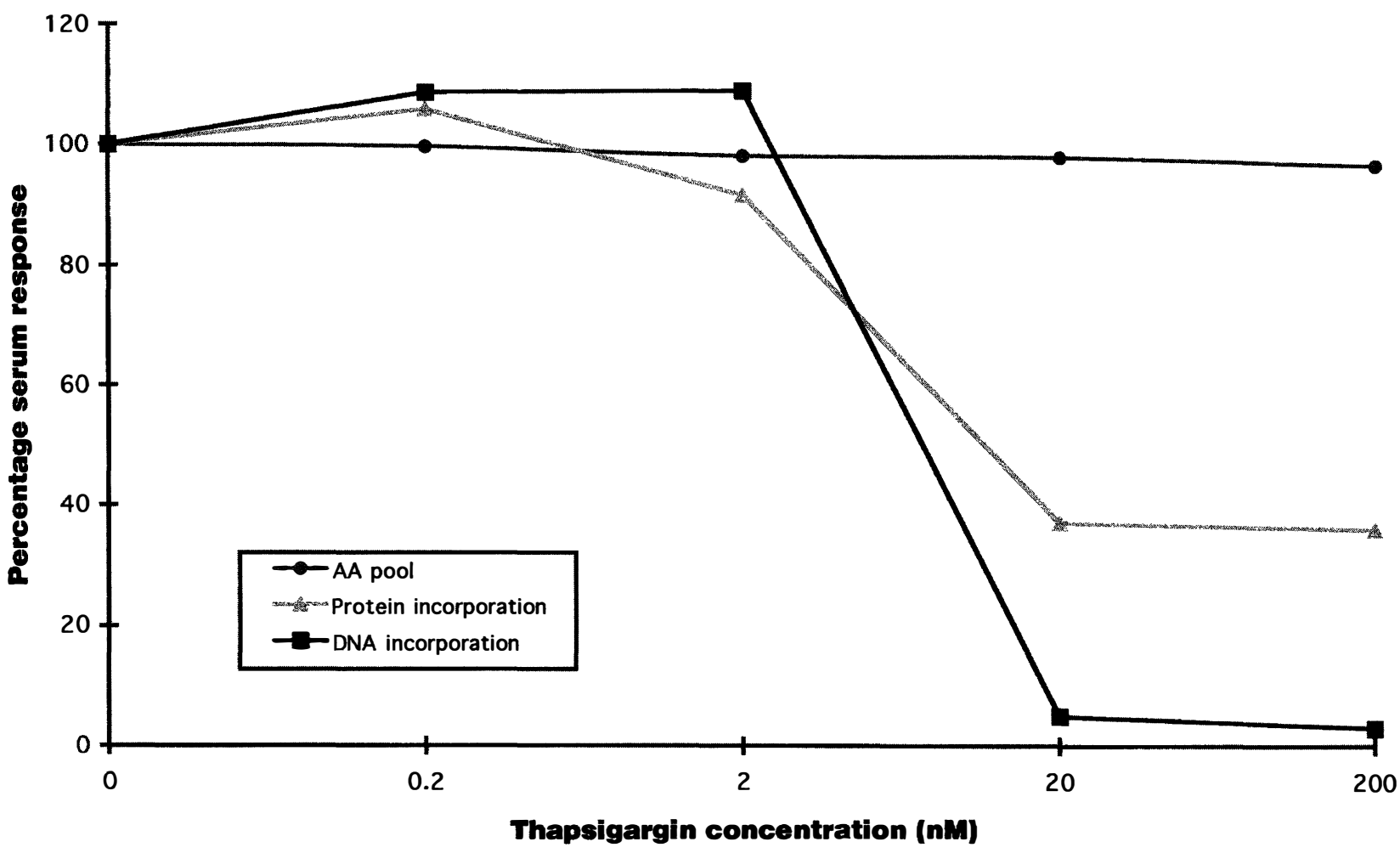

Fig. 2. Effect of thapsigargin on amino acid (AA) transport, protein incorporation and DNA synthesis in tissue-cultured lens cells. Note that while thapsigargin has little effect on transport at concentrations $>5 \mathrm{nM}, \mathrm{DNA}$ synthesis is totally inhibited.

thapsigargin inhibit cell division completely, protein synthesis is only partially reduced, while membrane transport mechanisms are unaffected (Fig. 2).

Interestingly, loss of endoplasmic reticulum activity is also associated with the final differentiation of epithelial cells into lens fibre cells and it is significant that, under these conditions, membrane transport processes can continue unimpeded.

It is likely that G-protein receptor agonists and growth factors interact to modulate cell growth in a complex manner, as calcium release from the stores by the former (e.g. in the form of ATP) can reduce growth while release by the latter (e.g. by PDGF) significantly increases cell division. ${ }^{25}$ Both types of agonist release diacylglycerol at the same time as producing $\mathrm{IP}_{3}$, but a complex and different array of kinases are activated in each case. Consequently, different transcription factors are produced and it is important that the different pathways for the production of these are identified in lens cells under different growth-modulating conditions.

\section{Calcium cell signalling and cataract}

It has been pointed out that a number of calcium cell signalling agonists and antagonists are implicated in human cataract. ${ }^{17}$ Exposure to cholinesterases, in particular, has been shown to be associated with an increased risk of cataract in both man and fish. ${ }^{26,27}$ These agents prevent the breakdown of acetylcholine and so would be expected to produce a hyperexcitation of acetylcholine receptors. Kaufman et al. ${ }^{28}$ have shown that such cataracts can be prevented by a concomitant application of atropine, suggesting that specific muscarinic receptors are involved. Human lens muscarinic receptors remain functional throughout life ${ }^{29}$ and so they are possible targets for cataract-inducing compounds during this time, including the iris, ciliary muscles and retina. These findings are also important in view of the fact that specific muscarinic agonists are currently being proposed as antiglaucoma agents, ${ }^{30}$ and it is vital that they do not target lens cells if the past experience with antiglaucoma agents is not to be repeated.

\section{Calcium cell signalling and posterior capsular opacification}

Posterior capsular opacification (PCO) results from the very robust growth of lens epithelial cells that remain after cataract surgery. ${ }^{31}$ An obvious way to prevent $\mathrm{PCO}$ is to inhibit lens cell growth, and the calcium store would seem to present a prime target for pharmacological intervention. In fact, the intraocular lens (IOL) itself would seem to provide an excellent drug delivery system if it could be coated with an adherent growth-inhibiting substance. Data from this laboratory indicate that thapsigargin is sufficiently hydrophobic to produce a coating that survives a sham cataract operation where an IOL is inserted into a human capsular bag. ${ }^{32}$ Subsequent culture of the bag with the coated IOL leads to total cell arrest and, at high coating concentrations, total cell death. Targeting the cell calcium store, therefore, provides a powerful method for preventing lens cell growth, and if suitable drug delivery systems could be 
developed it might also be applied to controlling cell growth in other conditions as diverse as proliferative retinopathy and cancer.

We wish to thank Dr Gregoire Thomas for many helpful discussions and The Humane Research Trust for funds to carry out the work.

\section{References}

1. Duncan G, Bushell AR. Ion analyses of human cataractous lenses. Exp Eye Res 1975;20:223-30.

2. Marcantonio JM, et al. Classification of human senile cataracts by nuclear colour and sodium content. Exp Eye Res 1980;31:227-37.

3. Hodge WG, Whitcher JP, Satariano W. Risk factors for agerelated cataracts. Epidemiol Rev 1995;17:336-46.

4. Leopold IH, Barnert AH. Steroids in ophthalmology. Adv Ophthalmol 1967;18:1-64.

5. Augusteyn RC. Protein modification in cataract: possible oxidative mechanisms. In: Duncan G, editor. Mechanisms of cataract formation in the human lens. New York: Academic Press, 1981:72-115.

6. Evans JR, et al. Age-related nuclear lens opacities are associated with reduced growth before one year of age. Invest Ophthalmol Vis Sci 1998;39:1740-4.

7. Jacques $\mathrm{PF}$, et al. Long term vitamin $\mathrm{C}$ supplement use and prevalence of early age-related lens opacities. Am J Clin Nutr 1997;66:911-6.

8. Leske MC, et al. Antioxidant vitamins and nuclear opacities: the longitudinal study of cataract. Ophthalmology 1998;105:831-6.

9. Spector A, Garner WH. Hydrogen peroxide and human cataract. Exp Eye Res 1981;33:673-81.

10. Azuma $M$, et al. Activation of calpain in lens: a review and proposed mechanism. Exp Eye Res 1997;64:529-38.

11. Duncan G, Jacob TJC. Calcium and the physiology of cataract. Ciba Found Symp 1984;106:132-48.

12. Sanderson J, Duncan G. pCMPS-induced changes in lens membrane permeability and transparency. Invest Ophthalmol Vis Sci 1993;34:2518-25.

13. Delamere NA, Paterson CA. Hypocalcaemic cataract. In: Duncan G, editor. Mechanisms of cataract formation in the human lens. New York: Academic Press, 1981:60-72.

14. Duncan $G$, et al. Human lens membrane permeability increases with age. Invest Ophthalmol Vis Sci 1989;30:1855-9.
15. Marcantonio JM, Duncan G, Rink H. Calcium-induced opacification and loss of protein in the organ-cultured bovine lens. Exp Eye Res 1986;42:617-30.

16. Hightower KR, Riley MV, McCready J. Regional distribution of calcium in alloxan diabetic lens. Curr Eye Res 1989;8:517-21.

17. Duncan G, Williams MR, Riach RA. Calcium, cell signalling and cataract. Prog Ret Eye Res 1994;13:623-52.

18. Vivekanandan S, Lou MF. Evidence for the presence of phosphoinositide cycle and its involvement in signal transduction in the rabbit lens. Curr Eye Res 1989;8:101-12.

19. Knorr M. Modulation of cytosolic free calcium concentrations by PDGF isoforms in cultured bovine lens epithelial cells. Exp Eye Res 1992;55:S623.

20. McAvoy JW, Chamberlain CG. Growth factors in the eye. Prog Growth Factor Res 1990;2:29-31.

21. Reid TW. Growth control of cornea and lens epithelial cells. Prog Ret Eye Res 1994;13:507-54.

22. Williams MR, et al. Acetylcholine receptors are coupled to mobilisation of intracellular calcium in cultured human lens cells. Exp Eye Res 1993;57:381-4.

23. Thomas GR, Duncan G, Sanderson J. Acetylcholine-induced membrane potential oscillations in the intact lens. Invest Ophthalmol Vis Sci 1998;39:111-9.

24. Thomas GR, et al. The human lens possesses actylcholine receptors that are functional throughout life. Exp Eye Res 1997;64:849-52.

25. Duncan $G$, et al. Calcium mobilisation modulates growth of lens cells. Cell Calcium 1996;19:83-9.

26. Shaffer RN, Hethrington J. Anticholinesterase drugs and cataract. Am J Ophthalmol 1966;64:613-8.

27. Fraser PJ, Duncan G, Tomlinson J. Effects of a cholinesterase inhibitor on salmon lens: a possible cause for the increased incidence of cataract in salmon Salmo solar. Exp Eye Res 1989;49:293-8

28. Kaufman PL, Axelsson U, Barany EH. Atropine inhibition of ecothiophate cataractogenesis in monkeys. Arch Ophthalmol 1977;95:1262-8.

29. Thomas GR, et al. The human lens possesses acetylcholine receptors that are functional throughout life. Exp Eye Res 1997;67:849-52.

30. Honkanen RE, Howard EF, Abdel-Latif AA. M3 muscarinic receptor subtype predominates in the bovine iris sphincter smooth muscle and ciliary processes. Invest Ophthalmol Vis Sci 1990;31:590-3.

31. Marcantonio JM, Vrensen GFJM. Cell biology of posterior capsular opacification. Eye 1999;13:482-6.

32. Duncan G, et al. Thapsigargin-coated intraocular lenses inhibit human lens cell growth. Nature Med 1997;3:1026. 